\title{
Eine marokkanische Staatsurkunde.
}

\author{
Mitgeteilt von
}

\section{G. Kampffmeyer.}

Mit zwei Tafeln.

In dem Augenblicke, wo die Geschicke des bisherigen Marokko sich vollenden, mag man sich besonders bewußt werden, welche Studienmöglichkeiten dem Islamforscher bisher dieses Land gewährt hat, das, vor den Toren Europas gelegen, sich wie kein zweites fremdem Einflusse verschloß und altererbte Institutionen auf das zäheste bewahrte. Man hat im letzten Dezennium in Frankreich diese Institutionen auf das eifrigste und sorgfältigste studiert. Zu diesem Studium möchte ich einen Beitrag liefern, indem ich das Original einer marokkanischen Staatsurkunde, durch welche die Absetzung von Mulai 'Abdu'l-'Azĩz und die Anerkennung von Mulai 'Abdu'l-Hafīẹ durch die 'Ulamā in Fes ausgesprochen worden ist, im Faksimile mit beigefügter Umschrift und Übersetzung mitteile. Meines Wissens ist eine Urkunde wie diese, die uns einen so interessanten unmittelbaren Einblick in die Modalitäten eines Thronwechsels gewährt, wie er in Marokko ähnlich sich so oft abgespielt hat, im Original noch nie mitgeteilt worden. Da sind die wunderlichen Notarschnörkel (بوخُشَّة خنفوسن oder), die in marokkänischen Urkunden eine so große Rolle spielen, da ist die grundsätzliche Genauigkeit der Redaktion, welche vorgekommene Fehler verbessert und die ausgeführten Verbesserungen und Zusätze urkundlich genau anmerkt, da ist ein neues, durch seinen staatsrechtlichen Inhait besonders interessantes Beispiel marokkanischer Beurkundung, in deren Besonderheiten man bisher eigentlich nur durch eine Arbeit von Dr. PhILIPP VASSEL I) recht eingeführt worden ist. Nun ist ja die von mir vorgelegte Urkunde - ich will mich in diesem Augenblicke so ausdrücken, werde mich aber sogleich verbessern müssen - schon

I) Über marokkanische Prozeßpraxis in: Mitteilungen des Seminars fïr Orientaliscke Sprachen zu Berlin, Jahrg. 5, Abt. 2, Berlin 1902. 
einmal übersetzt worden $\mathrm{x}$ ). Aber die Mitteilung gerade des Originaltextes ist von besonderem Interesse. Und sodann - hier muß ich meinen obigen Ausdruck verbessern, und das ist ein besonders interessanter Punkt - der Übersetzung, welche Herr MichauxBELLAIRE anfertigte, hat auf keinen Fall die von mir heute mitgeteilte Urkunde vorgelegen. Ist nun die eine Urkunde eine Abschrift der anderen? Sind zwei Originale angefertigt worden? Die nähere Betrachtung unserer Urkunde und die Vergleichung mit der Übersetzung des Herrn Michaux-Bellaire legt nun eine Vermutung nahe. Ganz zweifellos ist u n sere Urkunde original, was u. a. schon aus den eigenhändigen Unterschriften hervorgeht, aber eins springt auch bald in die Augen: unsere Urkunde ist unfertig. An einer Stelle ist die Lega-

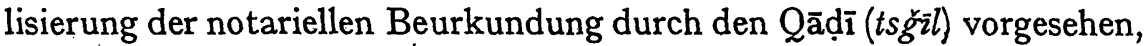
auch angefangen, aber dann nicht vollzogen (unten D). Diese Legalisierung an der bețr. Stelle ist vollständig übersetzt bei MichauxBellaire. Ferner an vier weiteren Stellen (nach $B, E, F$ und $H$ ) ist bei MICHAUX-BELLAIRE eine Legalisierung durch den Qãḍi vermerkt, wo unsere Urkunde eine solche Legalisierung nicht hat. Also der Qādīi, der mitwirken sollte, hat bei unserer Urkunde nicht mitgewirkt. Wie kam dies? Ich weiß nicht, ob die Erlangung der Mitwirkung des Qạdīs Schwierigkeiten gemacht oder sich in die Länge gezogen hat ${ }^{2}$ ), aber jedenfalls dürfte-unsere Urkunde, bevor der Qāḍi zur Mitwirkung gelangte, $a b h$ anden gekommen sein, so daß die Ausfertigung einer neuen Urkunde nötig wurde, die dann, unter Mitwirkung des Qādīs, zum Abschluß gebracht wurde und die, allem Anschein nach gleichfalls im Original, der Übersetzung des Herrn MichauX-Bellaire zugrunde lag. Ob diese zweite Urkunde sich noch in französischem Besitz befindet, weiß ich nicht; jedenfalls war sie zeitweise in französischen Händen. Nun vergegenwärtige man sich

x) Proclamation de la déchéance de Moulay Abd el Aziz et de la reconnaissance de Moulay Abd el Hafid par les Ouléma de Fès (Übersetzung von E. Michaux-Bellaire), in: Revue du Monde Musulman vol. 5, 1908, S. 424-435.

2) Eine Darstellung der Geschichte der Vorgänge jener Revolutionstage in Fes von berufener Seite wäre von hohem Interesse. Wollten doch auch die 'Ulamā zunächst $\mathrm{n}$ ich $\mathrm{t}$ ihre Fetwa geben und haben erst nach längerem Widerstreben nachgegeben! Sie hatten dazu guten Grund. Sie und alle Araber in Marokko, die unterrichtet zu sein glaubten, erwarteten, daß die Franzosen - wie man annahm, einem gegebenen Versprechen gemäB - Mulai 'Abdu'l-CAziz wieder einsetzen würden. Wäre dies geschehen, so hätten die 'Ulamā, die den Herrscher des Throns für verlustig erklärt hätten, Gefängnis und andere mißliche Folgen $z u$ gewärtigen gehabt. $\mathrm{Zu}$ der Fetwa schließlich gezwungen, haben sie sich durch Doppelsinnigkeiten, auf. die unten hingewiesen werden wird, zu helfen gesucht. 
doch einmal die Sachlage: Eine marokkanische Staatsurkunde von $\mathrm{d} \mathrm{e} m$ Inhalt und dieser Wichtigkeit kommt, ehe sie noch ganz fertig ist, abhanden und schließlich in $\mathrm{de} \mathrm{ut} \mathrm{sch}$ en Besitz (sie ist in meinen Händen). Die dann ncu aufgesetzte Urkunde kommt bald darauf in $f r a n z o ̈ s i s c h e$ Hände: kann man sich eine größere Zerfahrenheit der öffentlichen Verhältnisse denken als diese? Aber sie wirft cin Schlaglicht auf die Zustände, wie sie in diesem vempire qui s'écroule " geherrscht haben und die doch $a \mathrm{u} \mathrm{ch}$, neben anderen Kräften, durch ihre Morschheit den Zusammenbruch dieses Staatswesens bewirkten.

Inhaltlich deckt sich im übrigen die von Michaux-BeLlaire gegebene Übersetzung im allgemeinen mit dem Text unserer Urkunde. An einer Stelle freilich (in G, vgl. unten) fehlt in der französischen Übersetzung ein längerer Satz unserer Urkunde. Fehlte dieser Satz in jenem zweiten Original, oder ist nur die Übersetzung weggelassen?

Auch an einigen anderen Stellen dürfte der französischen Übersetzung ein Text vergelegen haben, der von dem, den unsere Urkunde aufweist, etwas verschieden war; bei einigen leichteren Abweichungen der französischen Übersetzung von unserem Text mag sich etwa auch der ausgezeichnete Übersetzer vom Original absichtlich freier gemacht haben.

Ich habe meine nach dem Original von mir gemachte Übersetzung durchgehends, nachdem ich sie gemacht, mit der französischen Übersetzung verglichen und in den Anmerkungen alle erheblicheren $\mathrm{Ab}$ weichungen der französischen Übersetzung notiert. So wird nun eine eindringende Beschäftigung mit diesem interessanten Schriftstück leicht möglich sein.

Einige Stellen (in G, vgl. unten) habe ich letzthin mit Herrn Dr. VASSEL, der gerade in Berlin war, durchgesprochen; ich bin ihm für mehrere Korrekturen dankbar. An einer Stelle, die mir unklar geblieben war und die auch in der französischen Übersetzung nicht zum Ausdruck kommt ( - es ist eine Stelle aus den oft so dunklen Rechtsbüchern -) habe ich Herrn Dr. VASSSELs Auffassung übernommen (vgl. unten) $\mathrm{r}$ ).

Die Größe des Originals unserer Urkunde entspricht, abgesehen von einem Punkt, genau der unserer ersten Tafel; die Länge des Papiers

r) Herr Dr. VASSEL hatte hernach noch die Güte, das Ganze in den Fahnenabzügen zu lesen und mir eine Anzahl von Bemerkungen zur Verfügung zu stellen, darunter wichtige Hinweisungen auf Tatsächliches sowie auf die charakteristischen Doppelsinnigkeiten des Textes. Ich habe diese dankbar verwertet. Das Nähere wolle man unten vergleichen. 
von oben bis unten, die Zwischenräume zwischen den einzelnen Abteilungen, der Rand oben, unten und an der $\mathrm{r}$ e chte $\mathrm{n}$ Seite decken sich genau mit dem Original. Nur der weiße Rand an der 1 in $k$ e $n$ Seite fehlt im Original: die Schrift tritt hier direkt an den Rand. Die zweite Tafel ist das Faksimile des oberen Teils der $\mathrm{R}$ ü ckseite des Originals; der Zwischenraum zwischen den beiden Absätzen, der Rand rechts und oben decken sich auch hier mit dem Original; nur der weiße Rand links fehlt auch hier im Original. Der untere Teil der Rückseite des Originals ist leer.

Das Original ist aus zwei Teilen zusammengeklebt (vgl. unten S. 83, E.); der untere Teil des oberen Stückes ist auf den oberen Teil des unteren Stücks geklebt; die Verbindung, d. h. der aufgeklebte untere Rand des oberen Stückes, verläuft dicht über den Zahlen 70-76 des Abschnittes C.

Die Urkunde ist nach der Art solcher marokkanischen Schriftstücke schmal zusammengefaltet.

Wir haben der leichteren Übersicht wegen die verschiẹdenen Abschnitte der Urkunde in der Umschrift und in der Übersetzung mit den Buchstaben $\mathrm{A}$ bis $\mathrm{H}$ bezeichnet. Es entsprechen in der französischen Übersetzung dem Abschnitt A S. 424-427, B S. 427-428, C (mit den I20 Unterschriften) S. 428-429, D S. 429-430, E S. 43043I, F S. $43 \mathrm{I}-432$, G S. $432-434$, H S. $434-435$.

Der Inhalt der verschiedenen Abschnitte ist in. Kürze dieser:

A. Die Notablen der drei Feser Stadtbezirke, deren Namen (nicht eigenhändig) unter dem Abschnitt stehen, erheben (naç $B$ und $E$ in ihrem Namen und im Namen der Bewohner der drei Bezirke) Anklage gegen Mulai 'Abdu'l-'Azīz und fragen die Gesamtheit der 'Ulamā von Fes, ob er auf Grund dieser Anklage abzusetzen ist.

B. Notarielle Beurkundung. des Aktes A. An diese notarielle Beurkundung ist in dem Exemplar, das der französischen Übersetzung zugrunde lag, der kurze Legalisierungsvermerk des Qāḍis angeschlossen ${ }^{x}$ ).

3) Er pflegt zu beginnen mit den Worten للم الميا "Lob sei Gott. Sie [die beiden Notare] haben [das Zeugnis] gebrachț". Darnach folgt in den Urkunden, die mir bekannt geworden sind und z. T. augenblicklich vorliegen, meist der Zusatz

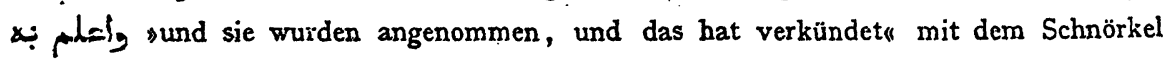
des Qãdiji. Vgl auch Vassel a. a. O. Nach Mrchaux-Bellaire würde hier auf die Unterschrift des Qãđịis noch eine weitere Unterschrift folgen. Herr Dr. VAsser möchte jetzt ثبل aktiv fassen: produxerunt, ergo acceperunt, iddemque enuntiat... 
C. 120 angesehene Personen (Schorfa, Schützen, Kaufleute usw.), deren Namen (nicht eigenhändig) am Ende folgen, bezeugen die Tatsachen, auf Grund deren die Anklage gegen den Sultan erhoben ist.

D. Beurkundung des Aktes $C$ durch den Qadi, in unserm Original abgebrochen, im Original, das der französischen Übersetzung zugrunde lag, vollständig, mit dem Qaḍischnörkel an der Stelle, wo unser Text abbricht, und den Unterschriften von zwei 'Adulen am Schluß (vgl. die Übersetzung unten S. 83).

E. Notarielle Beurkundung, daß die Fragesteller von A sowie unzählige andere Bewohner von Fes, auf Grund des ihnen durch die 'Ulama von Fes zuteil gewordenen (hier vorweggenommenen) Gutachtens von $G$; dem bisherigen Sultan den Gehorsam verweigern und sich nach einem anderen Sultan umsehen wollen.

Im Original, das den Franzosen vorlag, folgt hier wieder die Legalisierung durch den Qādĩ (und nach Michaux-Bellaire eine weitere Unterschrift).

F. Notarielle Beurkundung (Auszug aus einer besonderen Huldigungsurkunde) der Erwählung Mulai 'Abdu'l-Ḥafīẹ's durch die vorher Erwähnten:

Im Original, das den Franzosen vorlag, folgt hier wieder die Legalisierung durch den Qādīi, mit der Unterschrift von zwei weiteren Notaren (die zu den beiden, die die notarielle Beurkundung vollzogen, hinzukommen).

G. Das Gutachten der 'Ulamā von Fes mit deren eigenhändigen Unterschriften.

H. Eine größere Zahl von Notaren schließen sich in kurzen Erklärungen durch eigenhändige Unterschrift dem in der vorliegenden Urkunde notariell protokollierten Zeugnis der (120) Mengezeugen und dem Zeugnis der anderen Notare an.

Im Original, das den Franzosen vorlag, folgt wieder die Legalisierung durch den Q $\left.\bar{a} \operatorname{din}_{1} \mathrm{x}\right)$.

Groß-Lichterfelde bei Berlin, den I2. November IgII.

s) Ich gab den Inhalt nach der Reihenfolge der Urkunde. Zeitlich unả logisch gehört natürlich $G$ zwischen $C D$ und $E$. Herr Dr. VASSEL möchte den Inhalt in Kürze so gruppieren: I [= A. B.] Klage. II [= C.D.] Beweis des Tatbestandes. III $[=$ G.] Weistum. IV $[=\mathrm{E}$. $]$ Beschluß. V $[=\mathrm{F}$. $]$ Ausführungsvermerk. 


\section{Arabischer Text $\mathrm{x}$.}

A.

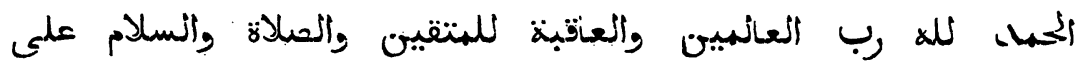

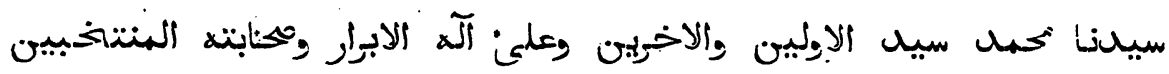

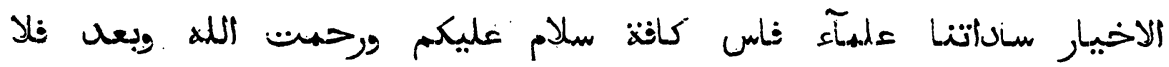

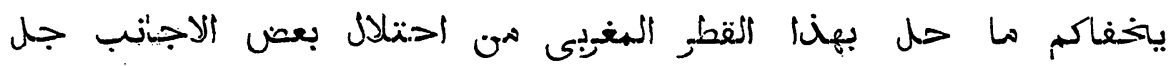
نواحيه كتوات وفجبيج زعبيون بنى مصأهز وملينة وجله وثنغر

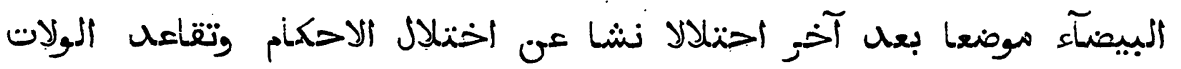

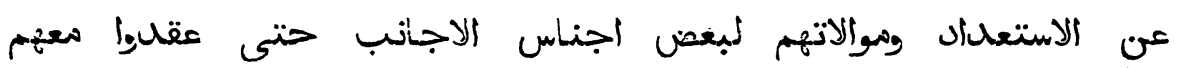
ثتروطا تودى الى الىخنا المسلمبن تحكت حكمهم وبسط يد التهمرف

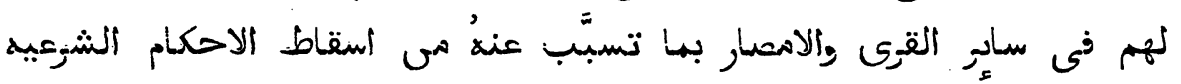

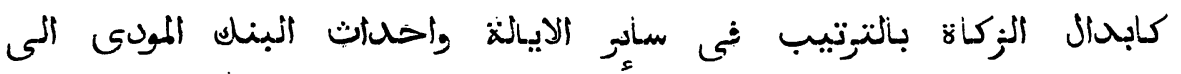

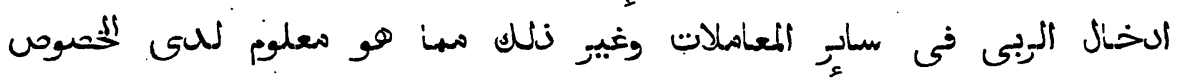

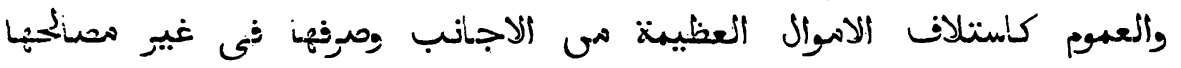

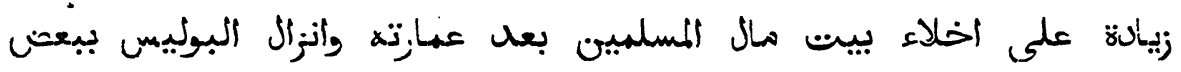
المرأسى اللذى مى أعظم دوالثيه سلب السملاح من يد كلى مسلم وغير ذللن

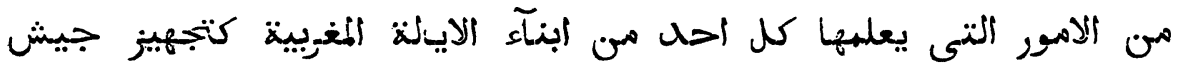

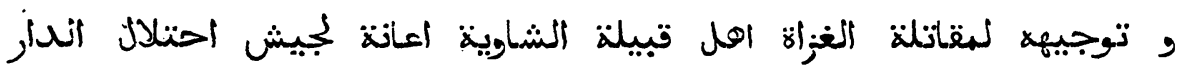

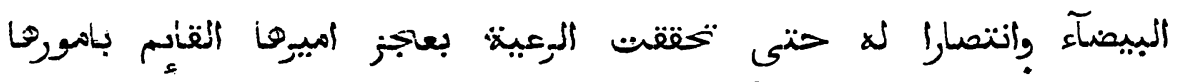

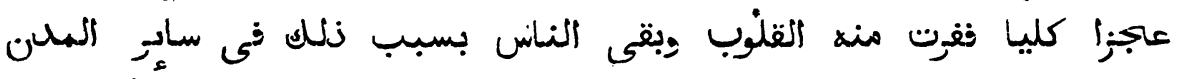

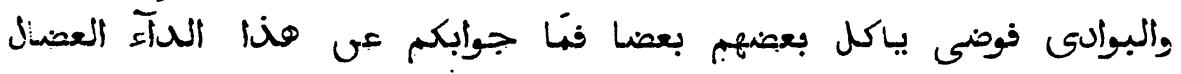

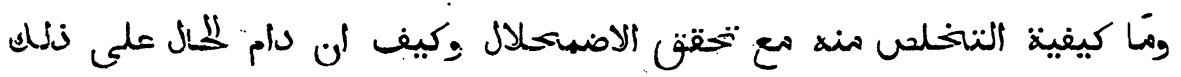

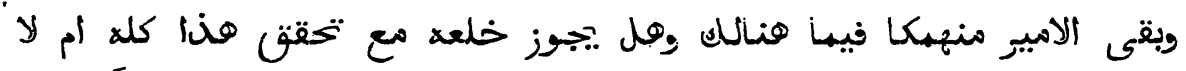

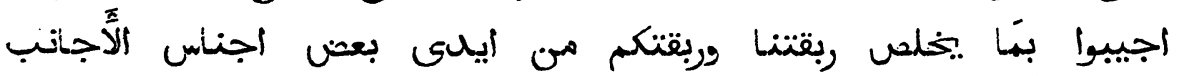

3) Die Zeichen für $f$ und $q$ sowie das Verdoppelungszeichen sind auf östliche Art wiedergegeben, die am Wortschluß fehlenden Punkte von $f, q$ und $n$ sind eingesetzt, die zwiefache Art der Schreibung von $\mathcal{} \checkmark$ am Wortschlu $B$ ist einheitlich wiedergegeben und statt $i_{\varepsilon}$ ist $T$ gedruckt. Im übrigen sind die Besonderheiten des Textes zum Ausdruck gebracht. - Es ist meist schwer zu entscheiden, ob „ي oder 2 gemeint ist. 


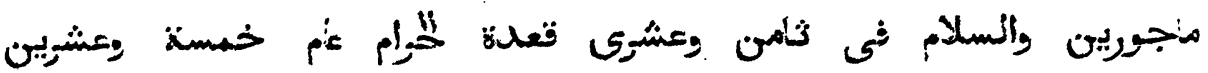
;ثلاثهية وأنف

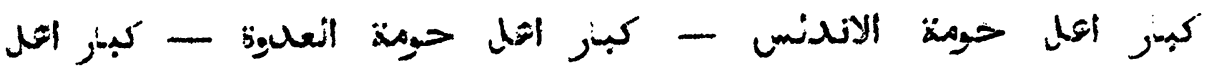
حومة اللمحنيين.

[Es folgen je unter jeder der drei Überschriften die Namen.]

B.

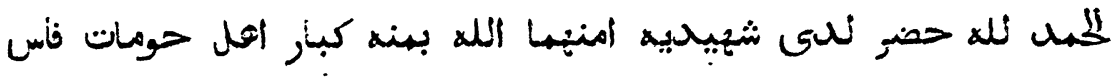

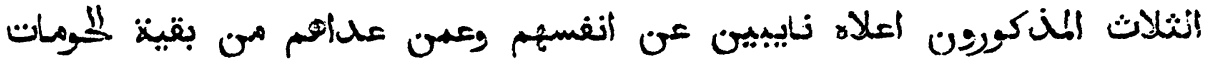

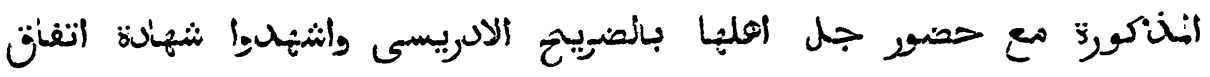

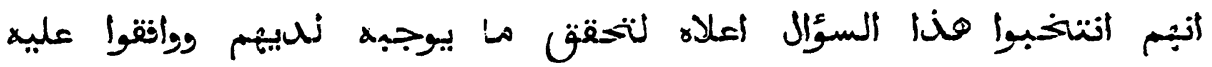

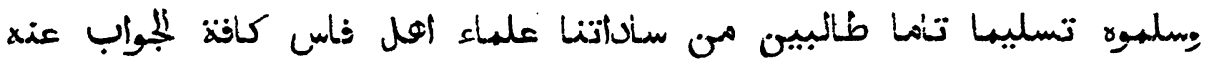

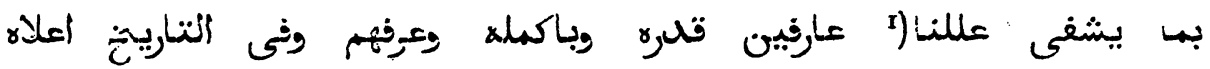

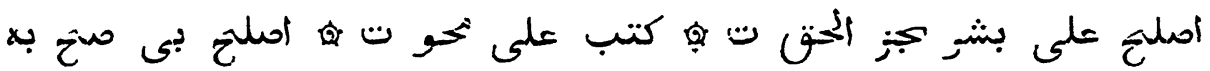

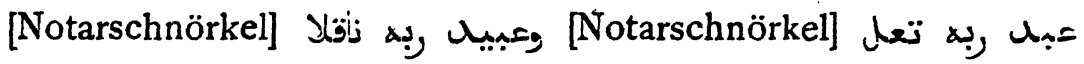

C.

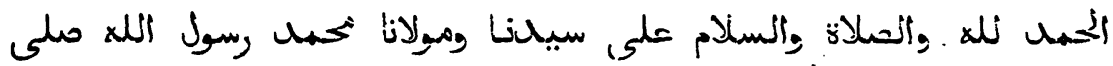

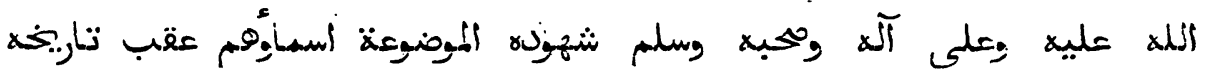

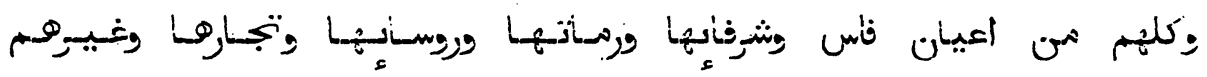

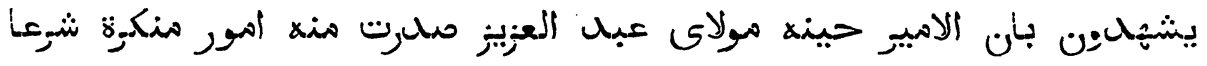

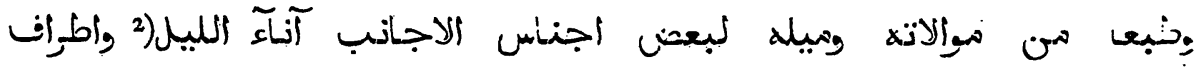

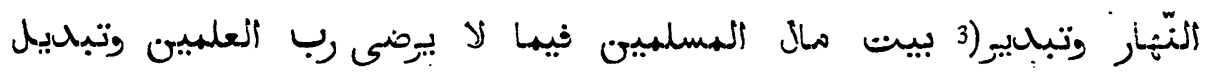

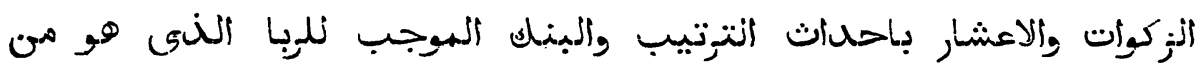

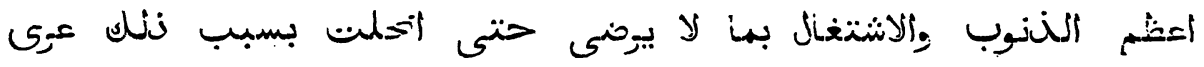

x) So. Die beiden in Faksimile über dem Wort noch erscheinenden Punlite sind im Original kleine braune Flecke.

2) Ms. اليل

3) So, statt تبنذيل. 
الدين وتفرقت جموع المسلمين وادى الكنال الى ثمكين بعض الاجنانب

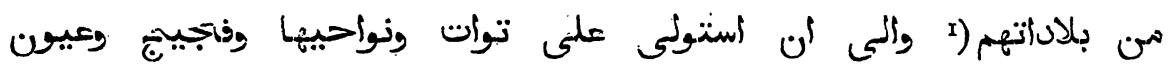

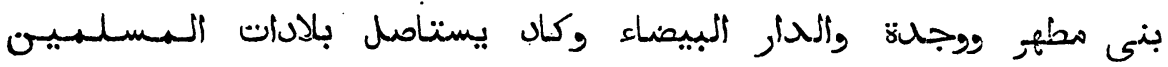

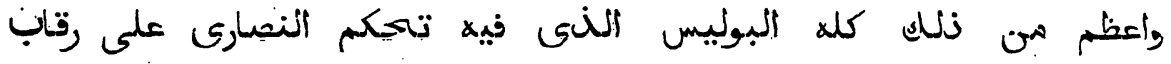

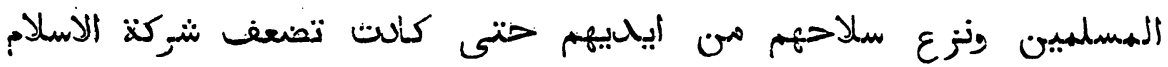

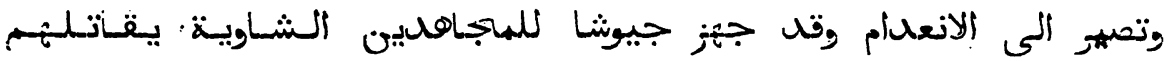

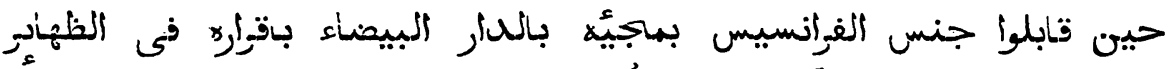

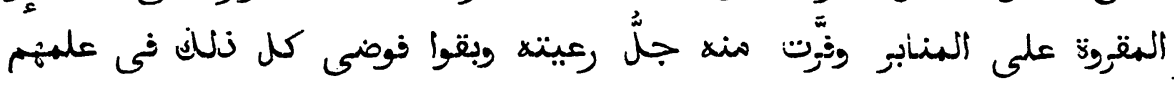

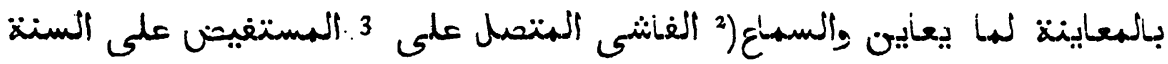

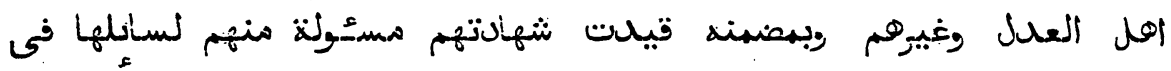

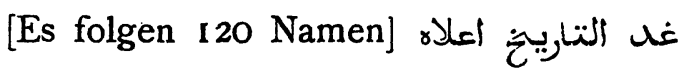

D.

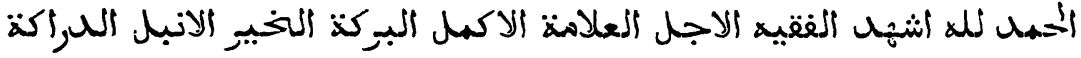

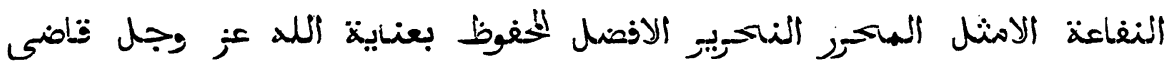

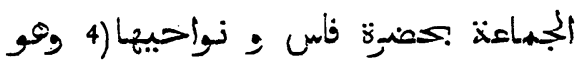

E.

الخحهل للع بعل مأ وقع سؤال من ذكر أعلاه مثي، أهل فأس المقيدة أسهائهم

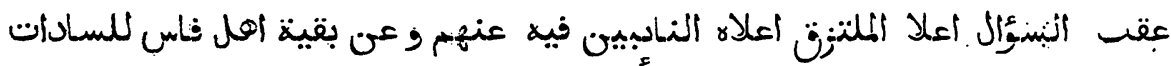

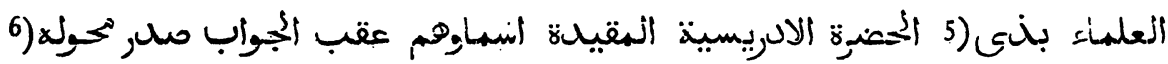

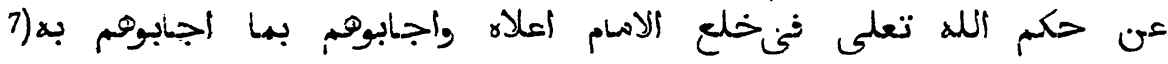

1) Das I nach U fehlt im Original oder ist doch nicht deutlich.

2) Auch im Original über w ein Strich (wohl $=e^{2}$

3) Über المتنصل على ein Strich.

4) ي ohne Punkt unten, statt dessen ein Punkt bezw. zwei Punkte oben.

5) Oder بـ? Der Anfang des Wortes ist nicht ganz deutlich, ? ist sicher.

6) Der im Faksimile über dem, erscheinende Punkt ist im Original ein brauner Fleck.

7) بst, erst hinter حيث حين uber die Zeile geschrieben, dann ausgewischt und

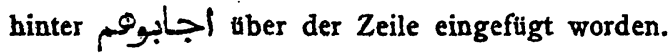


حيث أنثير استناد| منهم لها جلبوه من نصوص الإسنة رضوان. الله عليهم

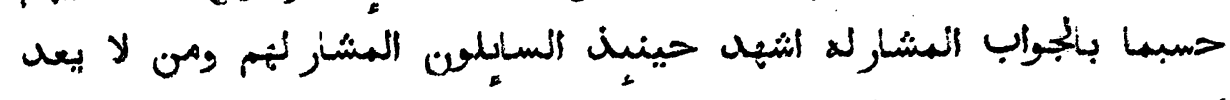

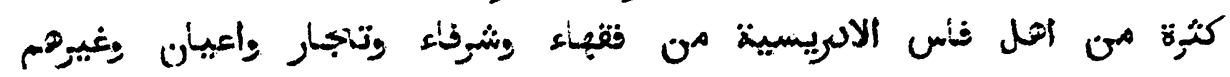

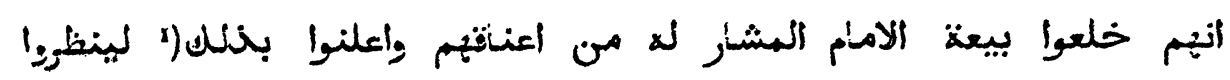

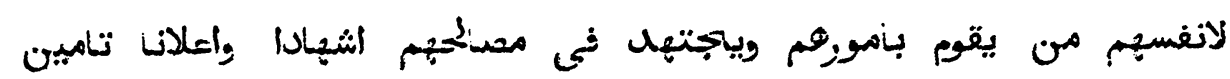

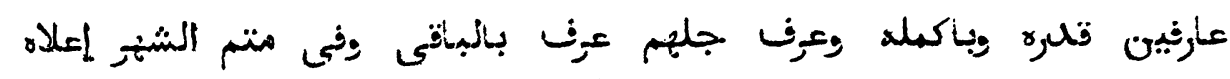

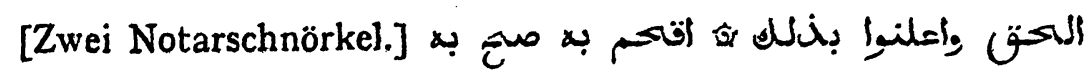

F.

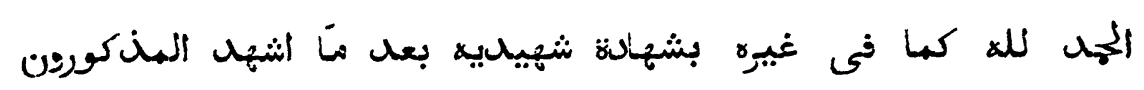

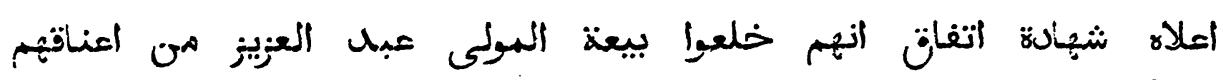

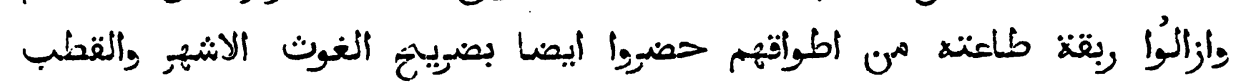

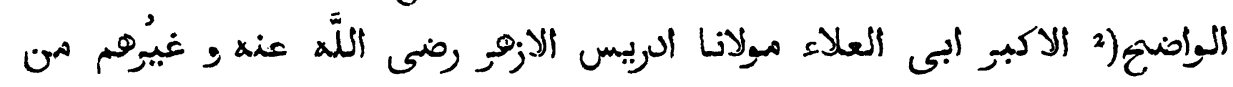

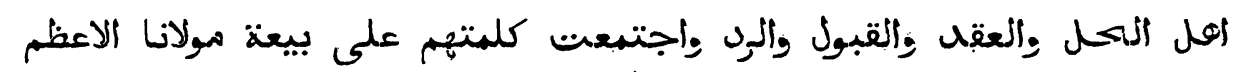

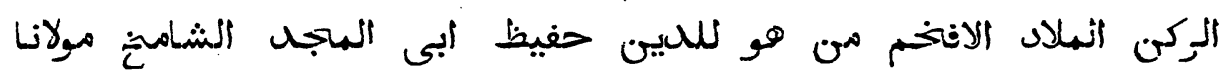

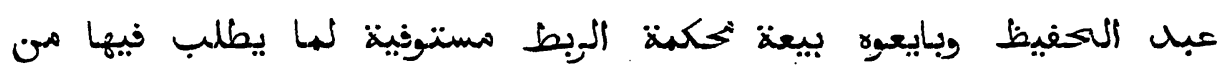

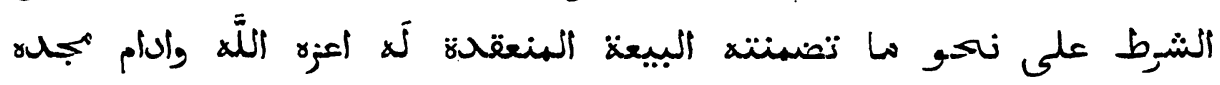

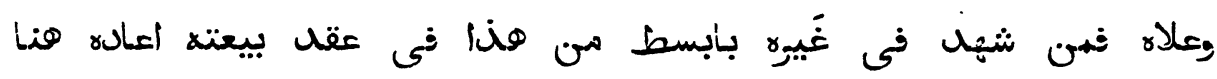

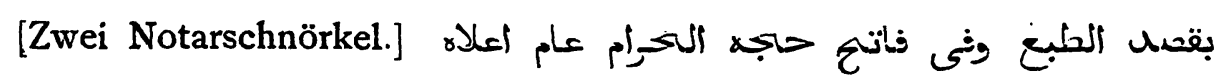

G.

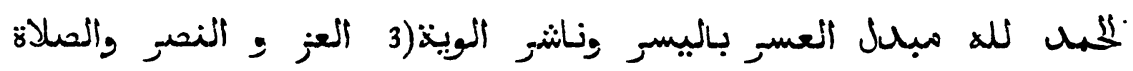

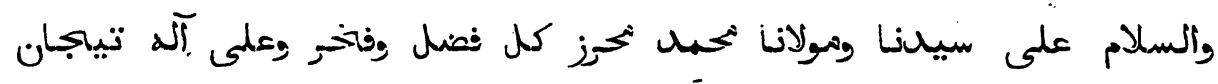

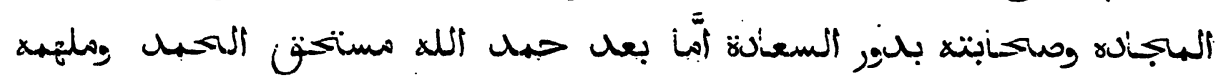

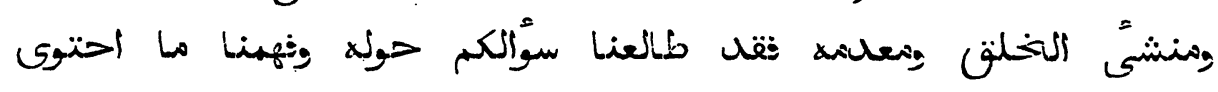

1) Dies und das vorhergehende Wort am Rande.

2) Der Punkt unter $\omega$ ist im Original nicht vorhanden.

3) Auf einer Rasur. 


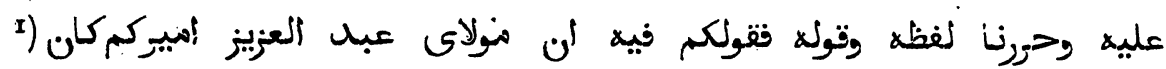

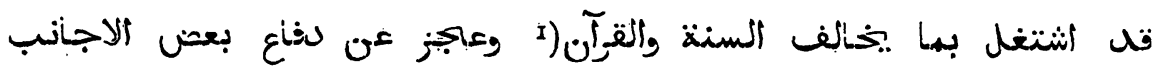

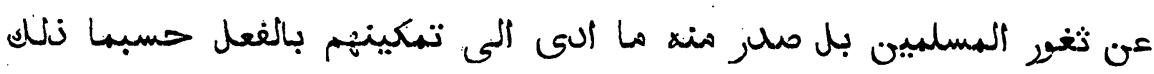

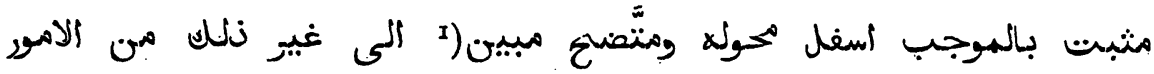

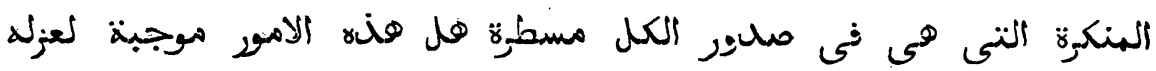

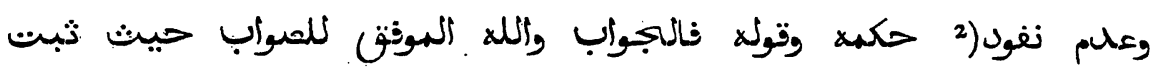

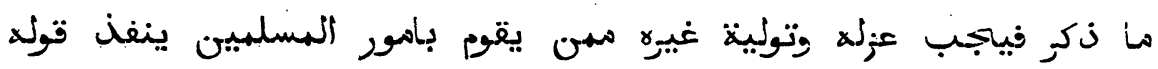

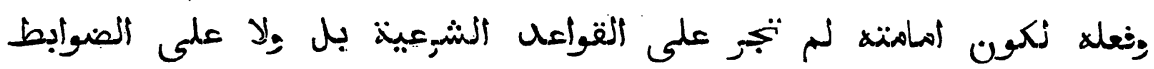

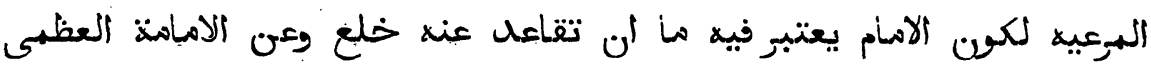

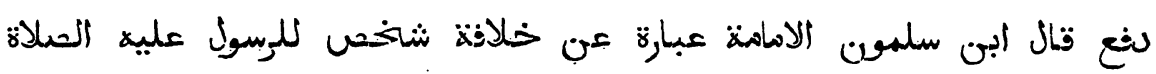

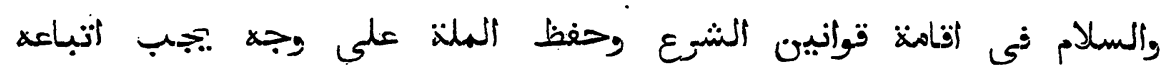

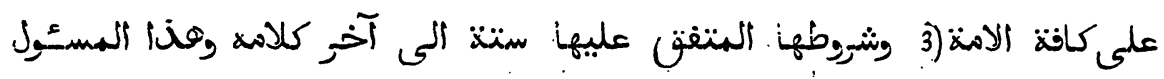

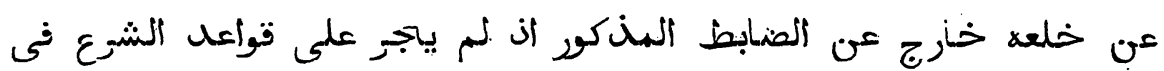

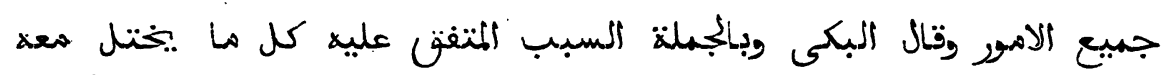

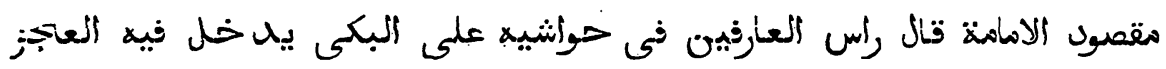

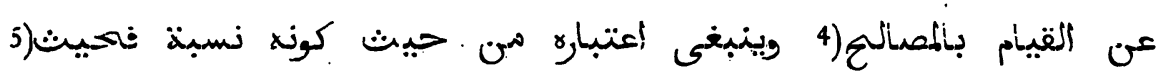

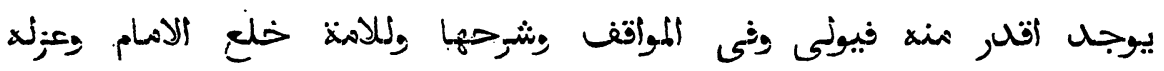

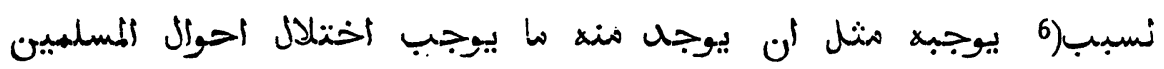

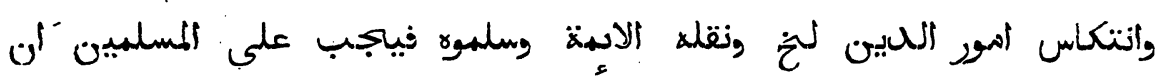

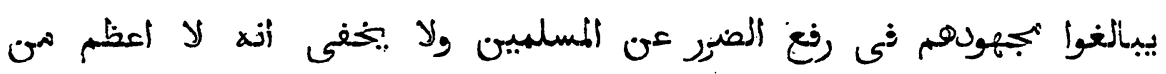

s) Über كان und an den folgenden Stellen das Zeichen (تف = (5), das in marokkanischen Urkunden und Briefen häufig zur Gliederung des Textes verwandt wird.

2) So, im Ms. mit $U$ statt mit .

3) Auf Rasur.

4) Zwei Punkte, die im Original auf ein langes $i$ vor $h$ zu deuten scheinen, könnon auch Flecke sein.

5) Das = ohne Punkt im Original.

6) Auch im Original wie im Faksimile 3 Punkte, also einer zu viel. 


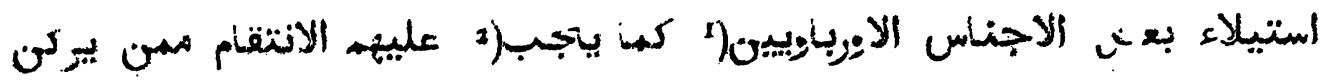

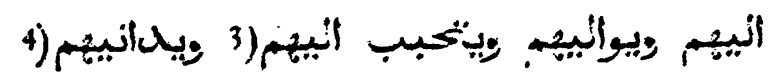

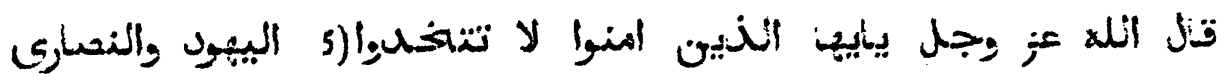

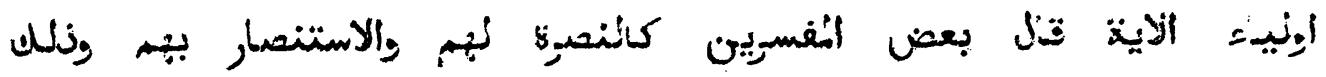

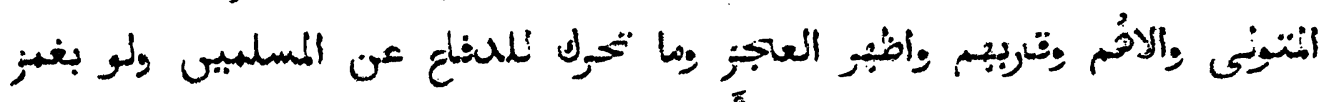

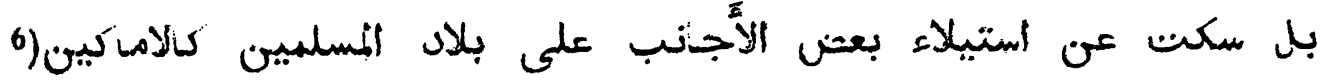

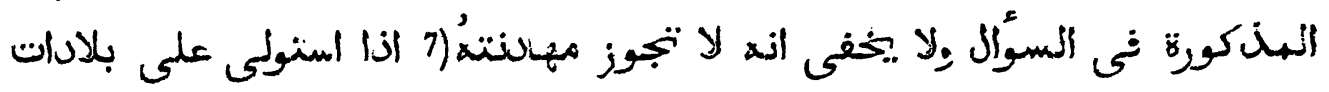

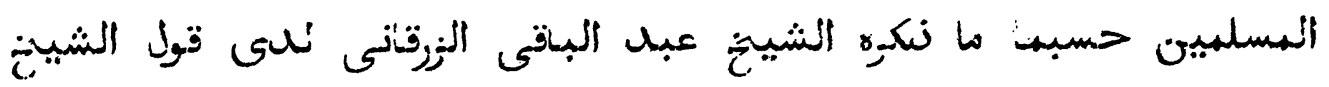

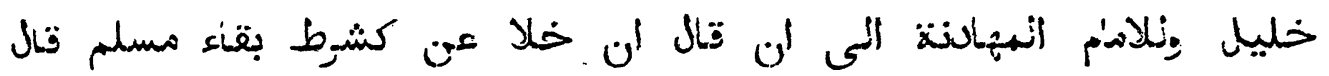

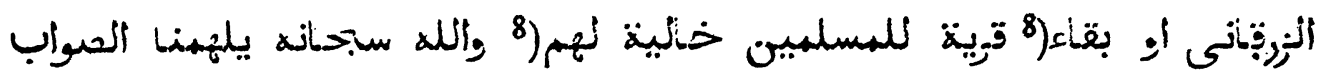

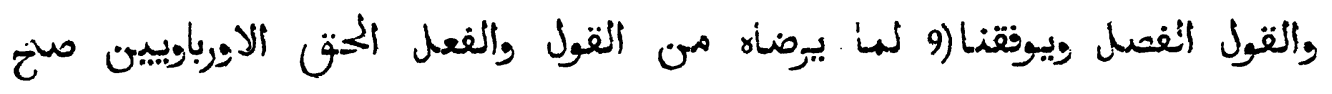

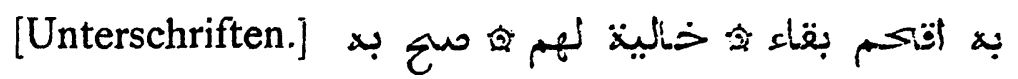
$\mathrm{H}$.

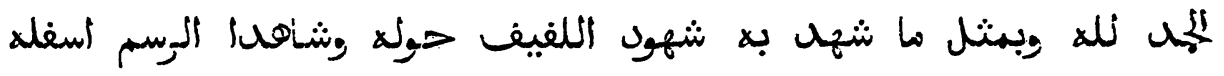

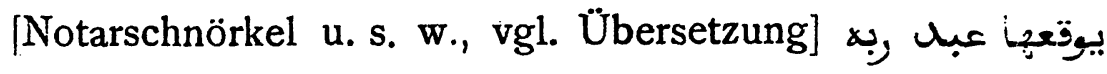
Übersetzung.

A.

Lob sei Gott, dem Herrn der Welten ${ }^{\mathrm{ro}}$ ), und der Ausgang ist derer, die sich Gott erwählten ${ }^{\mathrm{II}}$ ), und Segen und Heil über unsern Herrn Muhammed, den Herrn der an den Anfang und an das Ende Gestellten I2)

r) Am Rande.

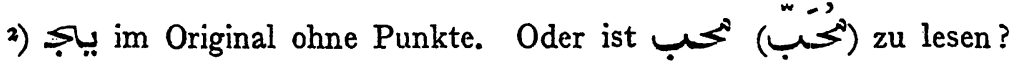

3) Im Original $ي$ mit 3 Punkten.

4) Über $j$ im Original nur e in Punkt, daneben ein kleiner brauner Fleck, der im Faksimile als Punkt erscheint.

5) Entweder, wie wir gedruckt, $\mathcal{J}$ ohne Punkt, oder es ist ein Punkt dem $\mathcal{U}$ zuzu weisen und es fehlt dann an andrer Stelle ein Punkt oder ein Punktpaar.

6) So mit langem $i$.

7) Der Anfang des Wortes auf einer Rasur.

8) بقالية لهم nachträglich über die Zeile geschrieben.

9) Ein Punkt im Original fälschlich unten statt oben gesetzt.

10) Koran I, I.

11) Koran 7, 125; 28, 83. Eigentlich: den Gottesfürchtigen.

r2) Eigentlich: der Ersten und der Letzten. I0-I2 reimen im Original. 
und über seine Familie, die gerechten $\mathrm{I}$ ), und seine Gefährten, die erwählten, die rechten ${ }^{x}$ ). An unsere Herren, die 'Ulamā von Fes insgeșamt. Heil sei über Euch und die Barmherzigkeit Gottes. Zur Sache: Es ist Euch nicht unbekannt, wie in diesem Lande Marokko eingesetzt ${ }^{2}$ ) hat eine Besetzung ${ }^{2}$ ) seiner Hauptgegenden durch Fremde - so von Tuat, Figig, 'Ujūn Beni Mathar 3), der Stadt Udschda und dem Grenzort Casablanca, von einem Ort nach dem andern - welche Besetzung ${ }^{2}$ ) entsprang der Zersetzung ${ }^{2}$ ) der Ordnungen und der Tatsache, daß diejenigen, denen oblag, zu beschließen 4), sich zu rüsten unterließen 4) und für gut fanden, sich anzuschließen 4) einem gewissen fremden Volke, soweit, daß sie mit den Fremden Verträge eingingen, die dahin führten, die Muhammedaner unter jener Herrschaft zu bringen und jenen eine Handhabe zu geben 5), ü be r a 11 in Stadt und Land zu schalten durch ${ }^{6}$ ) die Umstürzung der Ordnungen des muhammedanischen Gesetzes, die dadurch verursacht wurde, wie die Ersetzung der Armensteuer durch den Tertib 7) im ganzen Reiche, die Gründung der Bank ${ }^{8}$ ), die dazu führt, in allen Geschäften den Wucher einzuführen, und anderes, das in engeren und weiteren Kreisen bekannt ist, wie die Tatsache, daß erhebliche Anleihen bei den Fremden aufgenommen und dann unnütż verwandt wurden, nachdem vorher der Staatsschatz der Muhammedaner, der ehedem voll war, geleert worden war, ferner die Einrichtung der Polizei9) in einer Reihe von Hafenplätzen - der Polizei, unter deren unheilvollen Wirkungen obenan .steht, daß der Hand jedweden Muhammedaners die Waffen entrissen werden - und andere Dinge, die jedermann von den Einlassen]"

s) Reime.

$\Rightarrow$ Im Original Wortspiele. Für »einsetzen» eigentlich »einziehen [ $=$ sich nieder-

3) D. i. Rās el-'Ain (Berguent) am Wād Zā, südlich von Udschda, besetzt 1904. Vgl. Augustin Bernard, Les Confins Algéro-Marocains, Paris I911, S. 160. Ebenda auch Historisches über die Besetzung von Tuat und der Gegend bei Figig.

4) Im Original Wortspiel und Reim. Eigentlich: daß die Gouverneure vernach* lässigten die Rüstung und sich anschlossen.

5) Eigentlich: Ihnen die Hand zu öffnen des Schaltens in den übrigen [bzw. allen] Dörfern und Städten.

6) Oder $ب=$ ssamt৫. So: ... sund jenen in allen Flecken und Städten die Verwaltung zu überlassen, samt dem, was daraus folgt, als da ist die Abschaffung der mohammedanischen Rechtsregelnu. V.

7) Über diese Steuer-Neuordnung (Ackerbausteuer) vgl. u. a. Eug. Aubin, Le Maroc d'aujourd'hui, 2. éd. S. 254.

8) Algeciras-Akte Kap. 3 (Artikel 31-58).

9) Algeciras-Altie Kap. I (Artikel 1-12). 
wohnern des marokkanischen Reiches kennt, wie die Ausrüstung eines Heeres und seine Entsendung zur Bekämpfung der Streifzügler ${ }^{3}$ ), der Leutc des Schăwiastammes, zur Unterstützung des Besatzungsheeres von Casablanca und zum Siege für dieses, so daß die Untertanen von der völligen Ohnmacht des ihre Angelegenheiten vertretenden Fürsten fest überzeugt wurden und die Herzen sich von ihm wandten, und infolge davon überall in den Städten und auf dem Lande die Bevölkerung in Anarchie verfiel, indem einer gegen den anderen seine Gier richtete. Was sagt Ihr nun zu diesem bösen Übel, und wie ist von ihm loszukommen, wo doch feststeht das Dahinsiechen, und wie [soll es werden], wenn das so weitergeht und der Fürst sich weiter mit dem abgibt, was dort [vor sich geht] - und ist es erlaubt, ihn abzusetzen, wo doch alles dies feststeht, oder nicht? Gebt [uns] ein Gutachten, das unsere und Euere Schlinge [in der wir gefangen sind und Ihr gefangen seid] frei macht aus den Händen eines gewissen fremden Volkes, um (Dankes-) Lohn ${ }^{2}$ ). Mit Gruß. Am achtundzwanzigsten des heiligen [Dü'l-] $\mathrm{Qa}^{\mathrm{c}} \mathrm{da}$ des Jahres Dreizehnhundertundfünfundzwanzig [ $=2$. Januar 1908].

Die Ältestendes Bezirks al-Andalus.

[Es folgen die Namen 3).]

Die Ältesten des Bezirks al-'Adwa.

[Es folgen die Namen 3).]

Die Ältesten des Bezirks al-Lamțijinn.

[Es folgen die Namen 3).]

x) "Dem sentimentalen Wert der Worte entspräche besser: „der Helden vom Stamme der Schāwial. V.

2) So auch in der franz. Übersetzung (S. 426): Donnez-nous une réponse qui nous débarrasse de ce collier qui est passé autour de votre cou et du nôtre par certaines puissances étrangères, nous vous en serons reconnaissants. Das setzt مأجبورين voraus, und so ist offenbar zu lesen. Ich las erst فاجورين (mit Ergänzung eines Punktes) und wollte übersetzen: oaus den Händen eines verworfenen gewissen fremden Volkes «.

3) Die Namen sind von Michaux-Beldaire aufgeführt. Ich notiere folgende Abweichungen unseres Textes. a) al-Andalus. 6. Name: $\mathrm{H}$ a $\mathrm{m} \mathrm{mād} \mathbf{i}$ statt Hammād. 8. Name: Sỉdi Ṃ o h a m m ed statt Sidi Maho. b) al-'Adwa. 4. Name: Ha a d d ū statt

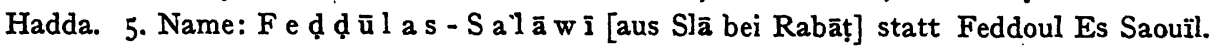
c) al-Lamtịiñ. I. Name: a ț-Tāheri statt Et Taher. 3. Name: ben $M \bar{u} \mathbf{l} \bar{a} \mathbf{i}$ Binnşar [Aussprache so nach Herrn Dr. V.] statt ben Sidi ben Nacer. Io. Name: ben 'O mar Lá's'ri oder La'sîri [Aussprache so nach Herrn Dr. V.] statt ben Amar El Aïdi. 
B.

Lob sei Gott. Es erschienen bei den beiden Zeugen dieses [Schriftstückes], Gott schütze sie mit seiner Gnade, die oben angegebenen Ältesten der drei Stadtbezirke von Fes in ihrem Namen und außerdem in Namen der übrigen [Bevölkerung] der erwähnten Stadtbezirke, unter Beisein der Hauptmasse ihrer Bevölkerung am Grabmale des Idrīs ${ }^{\mathrm{I}}$ ) und gaben übereinstimmend ${ }^{2}$ ) zu notariellem Protokoll, daß sie sich zu dieser obigen Frage entschlossen haben weil bei ihnen der sie begründende Tatbestand feststeht 3 ), und daß sie ihr $z u$ stimmen und sie giltig annehmen 4), indem sie von unseren Herren, den 'Ulamā der Bevölkerung von. Fes insgesamt, erbitten, daß sie darauf die Antwort geben, die unsere Leiden heilt - indem sie [die zu Protokoll Gebenden] die Tragweite dieses [Schriftstückes] kennen und geschäftsfähig sind, und sie [die Notare]5) haben sie gekannt. Am obigen Datum. Es ist verbessert ${ }^{6}$ ) worden auf einer Rasur $\left.; S^{7}\right)$; es ist hinzugefügt worden $\left.ت^{8}\right)$; es ist geschrieben worden auf einer Auswischung $ت 9)$; es ist eingebessert worden بـ Damit ist es richtig. Der Knecht seines Herrn des Höchsten [Notarschnörkel] und der kleine Knecht seines Herrn mitberichtend II) [Notarschnörkel] 12).

1) Die bekannte Moschee Mulai Idrīs in Fes

2) „Freiwillig". V.

3) In der franz. Übersetzung: ils ont déclaré qu'ils se sont consultés tous sur les questions posées ci-dessus, pour décider ce qu'ils devaient faire.

4) Sinn: Scharfe und definitiv für den Prozeß giltige Fixierung des Tatbestandes, analog dem حصر

5) $\mathrm{Zu}$ den Schlußformeln solcher Urkunden vgl. VAssed, Prozeßpraxis, S. 23 ff. und S. $38 \mathrm{ff}$.

6) In der franz. Übersetzung sind ähnliche Verbesserungen, wie sie hier und später notiert sind, nicht angemerkt.

7) Die Rasur, im Original deutlich zu sehen, liegt vor in A Zeile 7 in der zweiten Hälfte der Gruppe بعجي.

8) Siehe im Faksimile, B Zeile I, im Worte حومات

9) Der ausgewischte Buchstabe (eigentlich zwei) erscheint noch im Original, in A Zeile 7 in der Gruppe ففرت am SchluB.

10) Deutlich im Original A: Zeile 4, wo der Schluß von الكبي auf einer Rasur geschrieben ist. - Übrigens finden sich sonst noch im Original nicht angemerkte Rasuren, so eine in A Zeile 5, auf der das 0 der Gruppe النظ Vgl. außerdem S. 76,77 und 78 .

II) So V., mit dem Zusatz: d. i. der erste Notar hat manu propria geschrieben und gezeichnet, der zweite nur gezeichnet. Sonst ist üblich Leibl.

za) In der franz. Übersetzung folgt hier: Louange à Dieu. Ce document a été légalisé, approuvé et signé par le Qadi. (Signature illisible.)-Louange à Dieu, a signé et approuvé le contenu de la déclaration. (Signature illisible.)

Islam. IIf. 
C.

Lob sei Gott und Segen und Heil über unsern Herrn und Gebieter Mulammed, den Gesandten Gottes. Gott segne ihn und seine Familie und seine Gefährten und gebe ihnen Heil. Die Zeugen dieses [Schriftstückes], deren Namen hinter dem Datum dieses stehen - alle angehörend den angesehenen Familien, den Scherifen, den Schützen ${ }^{x}$ ), den Vorstehern, den Kaufleuten usw. von Fes - bezeugen, daß von dem augenblicklichen Fürsten Mulai 'Abdu'l-'Azīz Dinge ausgegangen sind, die anstößig sind nach göttlichem Recht und an sich ${ }^{2}$ ), wie daß er sich einer gewissen fremden Nation anschlo $B$ und zuneigte, in den Stunden der Nacht und an den Enden des Tages 3), und den Staatsschatz der Muhammedaner vergeudete für Dinge, die dem Herrn der Welten nicht wohlgefällig sind, und die Armensteuern und den Zehnten ablöste durch die Einführung des Tertīb und der Bank, die den Wucher bedingt, der einer der größten Sünden ist, und daß er sich beschäftigte mit [Gott] nicht Wohlgefälligem, so daß hierdurch alle Bande der Religion gelöst und die Vereinigungen der Muhammedaner zerrissen wurden und es dahin kam, daß einem gewissen fremden Volke die Gebiete der Muhammedaner überantwortet wurden, und daß es die Herrschaft ergriff über Tuat und Umgegend, über Figig, 'Ujūn Benī Mațhar, Udschda und Casablanca und den muhammedanischen Landen beinahe bis an die Wurzeln kam 4); und schlimmer als alles dies die Polizei, die in sich schließt die Herrschaft der Christen über die Nacken der Muhammedaner und das Fortnehmen ihrer Waffen aus ihren Händen, so daß der Verband des Islams fast seine Kraft verlor 5) und Vernichtung ihm stand bevor 5). Und er [der Sultan] hat Heere ausgerüstet gegen die im heiligen Kriege Stehenden, die Schāwia, um sie zu bekämpfen, als sie dem Volke der Franzosen ${ }^{6}$ ) bei ihrer Ankunft in Casablanca entgegentraten, nach 7) seinem [eigenen] Ge-

I) Schützengesellschaften sind über das ganze Land verbreitet; im Jahre I90I traf ich mit Angehörigen solcher Schützengesellschaften, die ins Freie eilten, bei Azemmur zusammen.

2) 》Nach Gesetz und von Natur.» V.

3) Koran 20, 130.

4) In der franz. Übersetzung (S. 429): ...ce qui a rendu possible l'occupation de leurs villes par certaines nations étrangères, la prise de possession du Touat et de ses dépendances, du Figuig, de Aïoun Beni Mathar, d'Oudjda et de Casablanca e $t \mathrm{~d}$ e $\mathrm{m}$ a $\mathrm{n}$ if e $\mathrm{s} \mathrm{t}$ e $\mathrm{r}$ l'intention d'occuper les villes des Musulmans.

5) Im Original Reim. Eigentlich: der Vernichtung entgegenging.

6) Hier zum ersten Male offen genannt.

7) Eigentlich »mit, durch». Es liegt wohl eine Gedankenellipse vor, etwa der Art: Das steht fest durch....... 
ständnis in den auf den Kanzeln verlesenen Erlassen, und es wendete sich von ihm die Hauptmasse seiner Untertanen und sie verfielen in Anarchie. Alles dies wissen sie durch den Augenschein eines Teiles und durch Hörensagen, das sich [in ununterbrochener Kette] ${ }^{\text {I) }}$ im Überschwange im Munde von zeugnisfähigen Leuten und anderen fortgepflanzt hat. Und in diesem Wortlaut ist ihr Zeugnis protokolliert worden, eingefordert von ihnen für seinen Einforderer an dem auf das obige Datum folgenden Tage [=3. Januar 1908].

[Es folgen I20 Namen, über jedem die laufende Nummer, über dem letzten aus Versehen IOzO statt I20.]

D.

Lob sei Gott. Es bekundet der erlauchte Rechtsgelehrte, der große Gelehrte, von dem der vollkommenste Segen ${ }^{2}$ ) ausgeht, der Gute, der Edle, der höchst Kluge, der den reichsten Nutzen Spendende, der Musterhafte, der geschickte, ganz vortreffliche Stilist, der durch den Schutz des großmächtigen Gottes Behütete, der Qāḍi der Gemeinde in der Residenz Fes 3) und ihrer Umgegend, nämlich [der Text bricht hier ab; Lücke 4)].

E.

Lob sei Gott. Nachdem die Frage der oben genannten Männer von Fes, deren Namen nach der Frage in der oberen Hälfte des oben Angeklebten 5) verzeichnet sind und die in ihrem Namen und im Namen

3). Über المتحفل على ist ein Strich (auch deutlich im Original), der, wie bekannt, eigentlich zur Hervorhebung dient, hier aber die Worte im besondern als solche hervorhebt, die zu tilgen sind. Es verhält sich mit diesem 》Tilgungse-Strich ähnlich wie mit einem andern »Tilgungs $<-Z e i c h e n$, das in der einen Ausfertigung des Mannesmann'schen »Berggesetzes « eine Rolle spielt und an das die Herren A. Fischer und neuerdings KAULisch (der Bearbeiter des arabischen Textes jenes Berggesetzes) Ausfälle über meine Unwissenheit geknüpft haben. Ich komme auf diese Dinge in anderem Zusammenhange zurück.

2) Auch hier und im folgenden im Original Reime, die wir hier nicht wiedergeben.

3) In der franz. Übersetzung (S. 429): ... le Qadi Ed Djemâa de Fes, la ville él e vé e d u M oula y Id ris et de ses environs. Die gesperrt gedruckten Worte haben in unserer Urkunde keine Vorlage.

4) Die franz. Übersetzung fährt hier fort: (...le Qadi...), c'est: (Signature illisible du qadi de Fes), que Dieu élève le Chérif et qu'il protège la ville de Fès, déclare confirmer absolument ce document ci-dessus ct les déclarations qu'il contient, qui sont conformes à ce qu'elles doivent être et qui constituaient, pour ceux qui les ont données, l'obligation de les faire. Faite à la date ci-dessus. (Suivent les signatures de deux Adoul.)

5) Vgl. oben S. 71. In der franz. Übersetzung (S. 430): ... par les gens de Fès dont les noms ont été cités après l'énoncé de cette question et qui y font suite. 
der iibrigen Bevölkerung von Fes sprachen, an die Herren 'Ulamā in dieser idrisitischen Residenz erhoben ist, deren Namen verzeichnet sind nach der Antwort [die sich findet] am Eingange des auf der Rückscite ${ }^{\text {I) }}$ Befindlichen über den Spruch Gottes des Höchsten, betreffend z) die Absetzung des oben erwähnten Imams, und nachdem diese jenen an besagter Stelle ihre Antwort gegeben haben, wobei sie sich stützten auf die von ihnen beigebrachten Textstellen der Imame [Kirchenlehrer] - Gottes Wohlgefallen sei über ihnen - wie [es] in der erwähnten Antwort [sich findet] 3), so haben alsdann die erwähnten Fragesteller und unzählige [andere] Männer aus dem idrisitischen Fes - Rechtsgelehrte, Scherifen, Kaufleute, angesehene Personen usw. - zu notariellem Protokoll gegeben, daß sie die dem erwähnten Imam geleistete Huldigung von ihren Hälsen abgeschüttelt und dies öffentlich verkündet haben 4), um sich jemand $\mathrm{zu}$ ersehen, der ihre Angelegenheiten vertrete und ihre Interessen nach bestem Ermessen wahrnehme, in gehöriger Form des zu Protokoll-Gebens und der öffentlichen Verkündigung, indem sie [jene Männer] den Inhalt dieses [Schriftstückes] kennen und geschäftsfähig sind, und sie [die protokollierenden Notare] haben die meisten von ihnen gekannt und sind mit den übrigen bekannt gemacht worden 5). Am letzten des obigen Monats [=4. Januar 1908]. Es ist hinzugefügt worden la l, (6) بذلكن 7); es ist eingeschoben damit ist es richtig. [Notarschnörkel] und der kleine Knecht seines Herrn [Notarschnörkel] ${ }^{8}$ ).

x) In der franz. Übersetzung: ci-dessous.

2) In der franz. Übersetzung: aux fins de savoir ce qu'ordonne Dieu tout-puissant.

3) Die franz. Übersetzung ist hier und im folgenden freier gegliedert, scheint aber auch nicht durchweg denselben Text wie in unserer Urkunde zur Vorlage gehabt zu haben. An dieser Stelle: ... ils ont répondu ce qu'ils ont répondu, e $t$ le u r rép on s ë a é té conforme a désirexprimédảns la question, appuyant leur décision sur les règles absolues des Imams, que Dieu les agrée, d' a c c ord e n $c$ e l a a ve e l' in tention de la question qui leur avait été posée.

4) Die den Worten »und dies öffentlich verkündet haben« entsprechenden Worte des arabischen Textes sind am Rande hinzugefügt.

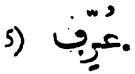

6) Siehe Faksimile am Rande.

7) Faksimile E Zeile 2 etwas vor der Mitte. به war erst hinter حيث hinzugefügt, ist dann ausgewischt und vor حيبت eingeschoben worden.

8) In der franz. Übersetzung folgt (S. 43I): Louange à Dieu, vérifié, accepté et signé par le Qadi. (Signature illisible.) Louange à Dieu, signé. (Autre signature illisible). 
F.

Lob sei Gott. Nachdem, wie an anderer Stelle ${ }^{\mathrm{I}}$ ) durch Zeugnis derselben beiden Zeugen dieses [Schriftstückes beurkundet steht], die oben Erwähnten zu übereinstimmendem ${ }^{2}$ ) notariellem Protokoll gegeben haben, daß sie die dem Mulai 'Abdu'l-'Azīz geleistete Huldigung von ihren Hälsen abgeschüttelt und die Fessel seines Gehorsams von ihren Nacken abgestreift haben, sind sie auch 3) im Grabmal des weitberühmten 4) Helfers und des glänzenden gewaltigen 4) Pols: des Erhabenen, unseres Herrn Idrīs des leuchtenden 4), Gott sei ihm wohlgefällig, mit anderen zum Entlasten und Verpflichten [der Gemeinde] und zum Annermen und Zurückweisen Befugten erschienen; und es einigte sich ihre Meinung darauf, $\mathrm{zu}$ huldigen unserm großmächtigen Herrn 5), dem Pfeiler, dem ruhmvollen Leitstern 5), der die Religion hütet ${ }^{6}$ ), dem erhabenen Glorreichen, unserm Herrn 'Abdu'l-Hafị 6), und sie haben ihm eine Huldigung geleistet, in der die Bindung [des Herrschers] genau ausgesprochen ist und die die in ihr geforderten Bedingungen voll zum Ausdruck bringt, nach Maßgabe des Inhalts der Huldigungsurkunde, die für ihn abgeschlossen worden ist, Gott mache ihn mächtig und gebe seinem Ruhm und seiner Hoheit Dauer. Und diejenigen, die an anderer Stelle Umfassenderes als dies in seiner Huldigungsakte bezeugten, haben es hier zum Zwecke der Besiegelung [Aktenabschließung. V.] wiederholt 7). Am ersten des heiligen [Dü'l-] Hiğğa des obigen Jahres. [Notarschnörkel] und der kleine Knecht seines Herrn des Höchsten [Notarschnörkel] ${ }^{8}$ ).

1) Es scheint mir, daß hier wie auch an späterer Stelle dieses Abschnittes der Urkunde ausgedrückt ist, daB die vorliegende Erklärung ein $A$ uszug a u s der gro $B$ en dem Sultan Mulai 'Abdu'l-Hafị gesandten Huldigungsurkunde ist. [Die kalligraphisch ausgeführte بيعن selbst ist über dem Grab von Mulai Idris aufgehängt worden, nachdem die von Mulai 'Abd el-CAziz dort entfernt worden war. V.] - Anders die französische Übersetzung (S. 43r): Louange à Dieu! - Par devant deux Adoul, comme pour tout autre document, après la déclaration consignée par les Adoul ci-dessus désignés, déclaration unanime que les déclarants annulent la proclamation de Moulay Abd El Aziz..

2) sFreiwillig zu ... Protokolle. V.

3) Denn die Proklamierung selbst war zunächst in der Qaruin-Moschee erfolgt. V.

4) Hier im Original Reime, die hier auch nicht wiedergegeben sind.

5) Im Original Reime; statt "Leitstern" eigentlich "Zuflucht».

6) Im Original Wortspiel mit hafid.

7) Franz. Übersetzung (S. 431): Ceux qui ont reçu les déclarations établissant cette proclamation afin qu'il en puisse être fait l'usage que de droit, renouvellent ici leur déclaration à ce sujet, comme il convient.

8) In der franz. Übersetzung folgt hier wieder (S. 432): Louange a Dieu. - Verifić et signé par le Qadi. (Signature illisible.) (Signatures illisibles de deux autres Adoul.) 
G.

Lob sei Gott, der an Stelle des Schweren I) das Leichte 1) setzt und die Banner der Macht und des Sieges entfaltet, und Segen und Heil sei über unserm Herrn und Gebieter Muhammed, dem Bewahrer aller Trefflichkeit und alles Ruhms, und über seiner Familie, der Glorie Kronen 2), und seinen Gefährten, den glückverheißenden Monden ${ }^{2}$. Zur Sache: Lob sei Gott, der das Lob verdient und es [sein Lob] in die Brust der Menschen senkt 3) und die Kreatur zum Leben ruft und dem Tode zulenkt 3). Wir haben Eure umstehende Frage gelesen und ihren Inhalt verstanden und ihren Wortlaut und was sie besagt, geprüft 4). Eure Rede ist, daß Mulai 'Abdu'l-‘Azĩz, Euer Fürst, der er gewesen ist 5), sich befaßt habe [Oder, die Worte anders bezogen: "daß Euer Fürst sich befaBt hatte", "ohne "der er gewesen ist " 6 )] mit dem, was mit der Sunna und dem Qoran im Widerspruch ist 5), und unfähig gewesen sei, gewisse Fremde von den Grenzen der Muhammedaner abzuwehren, vielmehr seien von ihm Maßnahmen ausgegangen, die dazu führten, ihnen [dieselben] tatsächlich zu überantworten, wie dies festgestellt sei in dem Dokument im unteren Teile des auf der anderen Seite 7) Befindlichen und deutlich sei und klargestellt, sowie anderes, was verabscheuungswürdig ist ${ }^{8}$ ) und in die Herzen aller geschrieben ist ${ }^{8}$ ). Bedingen diese Tatsachen, daß er abzusetzen ist und daß sein Urteil und sein Wort nicht mehr gelten sollen? Darauf [ist unsere] Antwort 9), aber Gott [allein] ist zum Richtigen Helfer und Hort 9). Sintemalen [Doppelsinn: weil oder sofern. V.] das Erwähnte feststeht, so ist Pflicht, ihn

x) Reime im Original.

2) Reime im Original.

3) Reime im Original.

4) Dozy gibt in diesem Sinne nur على Eigentlich: analysieren.

5) Reime im Original. In der franz. Übersetzung (S. 432) steht »notre Ëmir» wo in unserm Text steht أميركم كان.

6) Das wäre die zwanglose Übersetzung - und ist wohl eigentlich beabsichtigter Sinn der Stelle -, wenn nicht das Pausalzeichen über dem ك wäre, wodurch beim Vorlesen offenbar die Auffassung hervorgerufen werden sollte »der Euer Emir gewesen ist<. Dies schon gehört in das Kapitel der sogleich weiter zu besprechenden Doppelsinnigkeiten.

7) In der franz. Übersetzung (S. 432): ci-dessus.

8) Im Original Reime. - $>$ Abscheulichkeiten, die in eines jeden Brust eingeprägt sind " (Doppelsinn: »Ihr seid ja auch allzumal Sünder gleicher Sorte!«) V.

9) Im Original Reime. 
abzusetzen und jemand anders an die Spitze zu stellen, einen, der die Angelegenheiten der Muhammedaner vertritt. Sein Wort und seine Tat gelten darnach, daß sein ${ }^{\mathrm{I}}$ ) Imamat nicht vollzogen ist auf Grund der Regeln des heiligen Gesetzes 2), ja nicht einmal auf Grund der Festsetzungen, die [sonst] beobachtet werden ${ }^{2}$ ). Denn beim Imam ist [manches] $\mathrm{zu}$ beachten, bei dessen Unterlassung er abgesetzt 3) und des höchsten Imamats entsetzt 3) wird. Ibn Salmūn 4) sagt: "Imamat" ist ein Ausdruck dafür, daß eine Person den Propheten (Segen und Heil sei über $\mathrm{ihm}$ ) vertritt in der Aufrechterhaltung der Normen des heiligen Gesetzes und im Schutz der Kirchengemeinde auf eine Art, deren Nachachtung Pflicht ist für die Gesamtheit der Nation 5). Die Bedingungen für dasselbe [das Imamat], über welche Übereinstimmung herrscht, sind sechs usw. an der betr. Stelle. Dieser hier aber, über dessen Absetzung die Frage erhoben ist, ist aus der erwähnten Festsetzung herausgetreten [oder: fällt nicht unter jene Regel], da er nicht verfahren hat [Nebensinn: Da nicht verfähren worden ist in seiner Sache] nach den Regeln des heiligen Gesetzes in allen Angelegenheiten 6). Al-Bekkī sagt: Und, kurz gesagt, die Ursache [zur Absetzung], über die Übereinstimmung herrscht, ist alles, angesichts dessen der Zweck des. Imamats verdorben wird 7). Das Haupt der Wissenden bemerkt in seinen Randglossen zu al-Bekki: ... es fällt darunter auch die Ohnmacht zum Eintreten für die [allgemeinen] Interessen; und es ist angezeigt, diese [die Ohnmacht] aus dem Gesichtspunkt auch zu betrachten, daß sie ein relativer Begriff ist, wo

1) Man wird dies zunächzt so verstehen: ssein [des abgesetzten Sultans] Imamat«. Aber der Text ist doppelsinnig und besagt zugleich auch, daß das ne ue Imamat ungiltig ist. Klassisches Beispiel marokkanischer Doppelsinnigkeiten. V.

2) Im Original Reime, hier nicht wiedergegeben.

3) Reime im Original. - Die letztere Stelle ist in der franz. Übersetzung so wiedergegeben: car l'Imam qui est convaincu d'impuissance à combattre est déchu et a perdu tous ses droits à l'Imamat.

4) Die Rechtsbücher, aus denen dieser Text und die folgenden entnommen sind, stehen mir bis auf den Text des Sidi Halīl zurzeit zur Einsicht nicht zur Verfügung. Auch Mrchaux-Bellaire gibt eine Anmerkung nur zu der Stelle des Sidi Halìl.

5) Franz. Übersetzung (S. 433): Ben Salmoun a dit: "Imamat a le même sens que Khalifat et celui qui l'occupe est le représentant de l'Envoyé (de Dieu), sur lui salut et bénédiction, pour appliquer les prescriptions du Chrâa en toutes choses."

6) Die Worte unserer Urkunde von - in unserer Übersetzung von "Und die Bedingungen" bis »in allen Angelegenheiten" sind in der franz. Übersetzung gar nicht ausgedrückt.

7) Franz. Übersetzung (S. 433): El Bekki a dit: „En résumé, ce qui résulte de l'accord qui a été fait à son propos (de l'Imam), c'est que toute révolution qui est faite contre lui a pour cause l'Imamat (dont il a la charge)u. 
also einer da ist, der kraftvoller ist als er, da wird er an die Spitze gestellt "). Lind in den Mawäqif z) und ihrem Kommentar [heißt es]: Dic Nation hat das Recht, den Imam abzusetzen und ihn zu entfernen aus cinem dies nötig machenden Grunde, z. B. weil von seiner Seite her et was in die Erscheinung tritt, was den Verderb der I.age der Muhammedaner und die Umkehrung der Verhältnisse der Religion beclingt usw. 3). Und die Imame [Kirchenlehrer] haben dies übernommen und gutgeheißen. Darum haben die Muhammedaner die Pflicht, den größten Eifer zu entwickeln, um Schaden von den Muhammedanern wegzukehren, und es ist klar, daß es nichts Gewaltigeres gibt als die Usurpation einer europäischen 4) Nation, wie es weiter ihre Pflicht ist, Rache an dem zu nehmen, der sich jenen anvertraut, ihr Freund wird, ihnen Zuneigung beweist und ihnen nahetritt5).

Der großmächtige Gott hat gesagt ${ }^{6}$ ): " $\mathrm{O}$ ihr Gläubigen, nehmt Euch nicht die Juden und die Christen zu Freunden "7) [Ende des

3) Diese Stelle ist von mir mit Herrn Dr. VAssex durchgesprochen. Die Übersetzung vweil sie ein relativer Begriff ist" geht auf ihn zurück. Dr. VAsSEL übersetzte etwas freier: »Die Erklärung dieses Begriffes (عابك:, Unfähigkeit, Unzulänglichkeit) hat zu berücksichtigen, daß er etwas Relatives ist, also wo einer da ist, der".. usw. Die franz. Übersetzung lautet: $! \prod$ faut ajouter à cela l'impuissance à prendre les mesures nécessaires; dans ce cas ont doit surveiller celui qui est accusé de cette impuissance et si.l'on trouve un plus puissant que lui, il le remplacera. - Man sieht die verschiedene Auffassung; die Worte erscheinen gar nicht ausgedrückt.

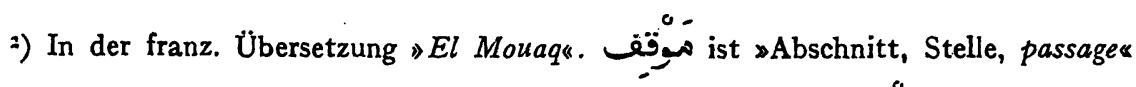
(wo man Halt macht beim Studieren, Lesen, wo der Lehrer sagt: ثقبف; daher denn das oben S. 77 besprochene Zeichen).

3) Franz. Übersetzung (S. 433): Dans El Moilaq et dans ses commentaires, il est dit que les sujets peuvent déposer l'Imam pour des raisons qui entrainent cette déposition, par exemple, s'il est le prétexte de troubles dans les affaires des Musulmans, ou s'il veut apporter des changements aux prescriptions religieuses, etc.

4) "europäischen« ist am Rande nachgetragen.

5) In diesem Satz kann man die Pronomina auch anders beziehen, und es wäre dann vielleicht auch eine andere, mir allerdings nicht klare, Interpretation möglich. Vgl: auch S. 78 Anm. 2 .

6) Koran 5, 56. [Hier kommt die persönliche Pique der CUlamā gegen M. Abdelasis wegen seines europäischen Verkehrs zum Durchbruch. $Z_{u}$ berücksichtigen ist dabei aber, daß gerade diesem Verse bekanntlich im Koran selbst anders urteilende entgegenstehen, und es darüber viele Kontroversen gibt. Die CUlamā sprechen hier also allerdings einen Tadel, aber keinen einwandfreien Absetzungsgrund aus. Auf die so naheliegende Ausführung, daß der Sultan die Franzosen um Hilfe angegangen hat, kommen sie in den tatsächlichen Ausführungen nicht zurück. V.]

7) Die franz. Übersetzung fügt, als dem Text angehörend, hinzu: „ Ils sont amis les uns dè autres». 
Qoran-]Vers[es]. Einer der Erklärer hat bemerkt: z. B. um ihnen zu helfen und sie um Hilfe anzugehen. Dieser Machthaber I) aber hat sịch an sie herangemacht $\mathrm{r}$ ) und hat sich ihnen genähert und Unfähigkeit gezeigt und sich nicht gerührt, die Muhammedaner zu verteidigen, nicht einmal eine Miene dazu gemacht, vielmehr geschwiegen zu der Tatsache, daß sich gewisse Fremde der Gebiete der Muhammedaner, wie der in der Frage erwähnten Örtlichkeiten, bemächtigten. Und es ist klar, daß Friedensschluß ${ }^{2}$ ) von seiner Seite nicht erlaubt ist, wenn sie sich der Gebiete der Muhammedaner bemächtigen, gemäß den Worten des Scheichs 'Abd al-Bāqī az-Zerqānī bei der Stelle des Scheih Halīl: Und der Imām hat das Recht des Friedensschlusses bis zu seinen Worten: Wenn er freibleibt z. B. von der Bedingung, daß ein Muhammedaner zurückbleibt 3). az-Zerqānī sagt [hierzu]: oder daß eine Ortschaft, die den Muhammedanern zukommt, frei bleibt für sie [die Fremden]. - Gott aber, Preis sei ihm, gebe uns ein das Rechte und den entscheidenden Ausspruch und helfe uns-zu den Worten und den Taten, an denen er Wohlgefallen hat. - Es wurde hinzugefügt: 4) الاوربأويين;; damit ist es richtig; es wurde eingeschoben 5) بقاء خالية لنيم 5und] damit ist es richtig.

[Es folgen eine größere Zahl eigenhändiger Unterschriften.]

H.

Lob sei Gott. Und ebenso wie bezeugt haben die Zeugen des umstehenden Mengenzeugnisses ${ }^{6}$ ) und die beiden Zeugen des Doku-

s) Im Original Wortspiel.

$\Rightarrow$ Da مجاد geben. - Auch hier ist die فتوى so gefaßt, daß sie mit Leichtigkeit zu widerlegen wäre. V.

3) Diese unsere Übersetzung stimmt wesentlich überein mit der franz. Übersetzung: ... ainsi que l'a dit le Cheikh... $\gg \mathrm{I}$ appartient à l'Imam de faire une trèvel et plus loin »si pour l'obtenir il n'est pas tenu à de certaines conditions, comme. par exemple d'abandonner un Musulman«; Ez Zerkani dit: »ou une ville des Musulmans». Hierzu gibt Herr Michaux-Bellaire die Anmerkung: Le mot passé par les Ouléma de Fès est: $\ddot{x}$ "pour l'avantage (des Musulmans)y. Pour ce texte de Sidi Khalil, chapitre Ed Djihad, la guerre sainte, et pour ses commentaires, cf. Archives Marocaines, vol. XI, Nr. I, "Une fetwa du Cheikh Sidia» p. I 33 et suivantes.

4) Vgl. Faksimile Zeile 9 am Rande; vgl. oben.

5) Vgl. Faksimile Zeile 12.

6). Belkassem Ben Sedira, Petit dict. ar.-français S. 487 gibt سيف لغيف als "actc de notoriétés. Franz. Übersetzung (S. 434): De même qu'ont témoigné les témoins appartenant à toutes les classes des habitants, et qui sont désignés plus haut, dont les témojgnages ont été recueillis par les deux Adoul qui ont signé ce document, témoigne également l'esclave de son Seigneur élevé: (Suivent un grand nombre de signatures). 
ments am Schluß desselben, legt es [das Zeugnis, die sahäda] nieder [unterschreibt] der Knecht seines Herrn [Notarschnörkel] und ... und ... [usw. es folgen weitere Notarschnörkel, unterbrochen von kurzen Sätzen, daß sich die Unterzeichner den andern Zeugnissen anschließen $\left.\left.{ }^{x}\right)\right]$.

1) In der franz. Übersetzung folgt wieder (S. 435): Louange à Dieu. - En signification ct acceptation des Adoul ci-dessus, a signé: (Signalure illisible du Qadi). 